\title{
BMJ Open Impact on percutaneous coronary intervention for acute coronary syndromes during the COVID-19 outbreak in a non-overwhelmed European healthcare system: COVID-19 ACS-PCI experience in Ireland
}

Niall Patrick Connolly (D) , ${ }^{1}$ Andrew Simpkin, ${ }^{2}$ Darren Mylotte, ${ }^{1}$ James Crowley, ${ }^{1,2}$ Stephen O'Connor, ${ }^{3}$ Khalid AlHarbi, ${ }^{3}$ Thomas Kiernan, ${ }^{4,5}$ Sacchin Arockiam, ${ }^{5}$ Patrick Owens, ${ }^{6}$ Amal John, ${ }^{6}$ Gavin J Blake, ${ }^{7}$ Sean Fitzgerald, ${ }^{7}$ Diarmaid Cadogan, ${ }^{7}$ Liesbeth Rosseel ${ }^{1}$

To cite: Connolly NP, Simpkin A, Mylotte D, et al. Impact on percutaneous coronary intervention for acute coronary syndromes during the COVID-19 outbreak in a non-overwhelmed European healthcare system: COVID-19 ACS-PCI experience in Ireland. BMJ Open 2021;11:e045590. doi:10.1136/ bmjopen-2020-045590

\section{- Prepublication history for} this paper is available online. To view these files, please visit the journal online (http://dx.doi. org/10.1136/bmjopen-2020045590).

Received 06 0ctober 2020 Revised 25 February 2021 Accepted 15 March 2021

Check for updates

(C) Author(s) (or their employer(s)) 2021. Re-use permitted under CC BY-NC. No commercial re-use. See rights and permissions. Published by BMJ.

For numbered affiliations see end of article.

Correspondence to Dr Niall Patrick Connolly; niallcon@gmail.com

\section{ABSTRACT}

Aims To evaluate temporal trends of acute coronary syndromes (ACS) treated via percutaneous coronary intervention (PCI) throughout the COVID-19 outbreak in a European healthcare system affected but not overwhelmed by COVID-19-related pathology.

Methods and results We performed a retrospective multicentre analysis of the rates of $\mathrm{PCl}$ for the treatment of ACS within the period 2 months pre and post the first confirmed COVID-19 case in Ireland, as well as comparing $\mathrm{PCl}$ for ST-elevation myocardial infarction (STEMI) with the corresponding period in 2019. During the 2020 COVID-19 period (29 February-30 April 2020), there was a $24 \%$ decline in $\mathrm{PCl}$ for overall ACS (incidence rate ratio (IRR) 0.76 ; $95 \% \mathrm{Cl} 0.65$ to 0.88 ; $\mathrm{p}<0.001$ ), including a $29 \%$ reduction in PCI for non-ST-elevation ACS (IRR 0.71; $95 \% \mathrm{Cl} 0.57$ to $0.88 ; \mathrm{p}=0.002$ ) and an $18 \%$ reduction in $\mathrm{PCl}$ for STEMI (IRR 0.82; 95\% Cl 0.67 to $1.01 ; \mathrm{p}=0.061$ ), as compared with the 2020 pre-COVID-19 period (1 January-28 February 2020). A 22\% (IRR 0.78; 95\% Cl 0.65 to $0.93 ; p=0.005$ ) reduction of $\mathrm{PCl}$ for STEMI was seen as compared with the 2019 reference period.

Conclusion This study demonstrates a significant reduction in $\mathrm{PCl}$ procedures for the treatment of ACS since the COVID-19 outbreak in Ireland. The reasons for this decline are still unclear but patients need to be encouraged to seek medical attention when cardiac symptoms appear, in order to avoid incremental cardiac morbidity and mortality due to a reduction in coronary revascularisation for the treatment of ACS.

\section{INTRODUCTION}

The COVID-19 pandemic has brought many challenges for healthcare systems and has had a huge impact on social behaviour. To minimise the spread of infection, social distancing measures and wide restrictions in the movement of people have been
Strengths and limitations of this study

- This is a retrospective multicentre analysis of the temporal trends of acute coronary syndromes (ACS) treated via percutaneous coronary intervention (PCI) throughout the initial COVID-19 outbreak in Ireland.

- The participating centres account for $79.6 \%$ of all ST-elevation myocardial infarction presentations in Ireland, giving a very good representation of the overall national picture.

- The figures represent daily numbers of $\mathrm{PCl}$ procedures for the treatment of ACS, rather than hospital admission for $\mathrm{PCl}$ which could underestimate the true incidence of ACS presenting to hospitals due to alterations in clinical practice patterns, such as a potential for increased use of non-invasive strategies.

- The analysis was performed interyear and intrayear thus allowing the assessment for confounding by seasonable variations in presentations with ACS.

- The overall impact on cardiovascular and mortality hard outcomes are not currently measurable within the remit of this study and detailed demographic information including socioeconomic status, age, gender and comorbidities was not available for analysis.

implemented. Intermittent deferral of nonurgent and elective care has been a central tenet to increase hospital capacity to deal with the surge in COVID-19 cases and to avoid unnecessary exposure of patients to a hospital environment where COVID-19 may be more prevalent.

Initial expectations would have been for an increase in acute coronary syndrome (ACS) presentations in line with existing evidence suggesting a link between 
respiratory infections and subsequent myocardial infarction. ${ }^{12}$ However, first reports during the initial phase of the COVID-19 outbreak showed a decline in presentations of ST-elevation myocardial infarction (STEMI) and hospital admissions for ACS, even in geographies where the healthcare system was not overwhelmed by COVID-19 pathology. ${ }^{3-8}$ As percutaneous coronary intervention (PCI) has a proven beneficial outcome in the management of ACS, there is a concern that a similar decline in PCI procedures during the COVID-19 pandemic could lead to incremental cardiac morbidity and mortality. ${ }^{9}$

This study represents data from Ireland, a European country where widespread social and lockdown measures were implemented during the first wave of the COVID-19 outbreak, and the healthcare system has been affected, but not overwhelmed by COVID-19-related pathology. Our goal is to evaluate temporal trends of ACS treated via PCI during and before the COVID-19 outbreak in a European healthcare system affected but not overwhelmed by COVID-19-related pathology.

\section{METHODS}

In this multicentre retrospective registry, we examine the daily rates of PCI performed for the treatment of ACS during three different time periods in relation to the COVID-19 outbreak in Ireland. Participation was voluntary and data were anonymously collected by each participating centre in a dedicated electronic dataset. Cases were identified by combining cardiac catheterisation laboratory records showing performed PCI and hospital admission records. The data were cross-referenced with patient's paper and electronic records to provide accurate descriptors of the indication for PCI based on European Society of Cardiology (ESC)-defined diagnoses. Variables were categorised according to the indication and timing of PCI. National data regarding the COVID-19 outbreak were collected from the official Department of Health resources. ${ }^{10}$

\section{Patient and public involvement}

Patients or the public were not involved in the design, or conduct, or reporting, or dissemination plans of our research.

\section{Study population}

The Health Service Executive-dedicated ACS Programme designates six primary PCI centres in Ireland. ${ }^{11}$ In this study, the data are collected from five primary PCI facilities (Galway University Hospitals, Mater Misericordiae University Hospital Dublin, St James's Hospital Dublin, University Hospital Limerick and Waterford University Hospital). The five participating centres in this study account for $79.7 \%$ of all STEMI presentations in Ireland (estimated population: 4.90 million in 2020) based on the latest published national data. ${ }^{12} 13$ This study does not include any private healthcare facilities which also treat
non-ST-elevation ACS (NSTE-ACS) during office hours, but not STEMI cases.

\section{Definitions}

The daily rates of PCI procedures performed only for the treatment of ACS (ACS-PCI) during three delineated time periods were included in this study. The overall PCI group ('all ACS') was dichotomised into two groups, as defined by the ESC guidelines: (1) 'STEMI' and (2) 'NSTE-ACS', with the latter representing PCI performed for both non-STEMI and unstable angina. ${ }^{14}{ }^{15}$ Daily ACS-PCI rates were collected for three separate time periods: (1) the '2020 COVID-19' period, was set from the date of the first confirmed COVID-19 case in Ireland, 29 February 2020 until 30 April 2020 (62 days); (2) the '2020 pre-COVID-19' including 1 January-28 February 2020 (59 days); and (3) the '2019 reference' period covering January-April 2019 (120 days). Daily PCI rates for STEMI were collected for the '2019 reference', '2020 pre-COVID-19' and the '2020 COVID-19' periods, while data regarding PCI performed for the treatment of NSTE-ACS were collected for the '2020 pre-COVID-19' and '2020 COVID-19' periods.

In Ireland, phased containment and delay strategies were initiated on a national level in order to reduce the peak impact of the COVID-19 pandemic and slow the spread of the disease in the community. During the initial containment phase, all confirmed cases were isolated in COVID-19-designated hospitals (all participating hospitals), and there were local school/business closures where there had been contact with an infected patient. Measures steadily progressed in the delay phase with the closure of all schools from 13 March and a ban on mass gatherings, closure of all pubs/bars on 16 March, progressing to other non-essential services on 25 March and a full country-wide lockdown by 28 March (figure 1). Importantly, these measures were enforced at a national level without regional variability and continued for the duration of the studied period.

\section{Statistical analysis}

The data collected are daily counts of ACS-PCI procedures across the five participating centres. Hence, a negative binomial model was used to compare the effect of the COVID-19 pandemic on the rate of daily interventions due to (1) STEMI, (2) NSTE-ACS and (3) all ACS, while allowing for overdispersion in the daily rate of PCI procedures. Individual hospital was included as a random effect in all models, to account for clustering of data within settings. The '2019 reference' and the '2020 preCOVID-19' periods are compared with the more recent '2020 COVID-19' time period. Results are presented as incidence rate ratios (IRRs) along with corresponding 95\% CIs and $\mathrm{p}$ values. The IRR represents the ratio of the current rate of PCI relative to the preceding rate. IRR values below 1.0 suggest a reduction in PCI over time, whereas values above 1.0 would suggest an increase in PCI. Continuous variables, such as the mean daily rate of 

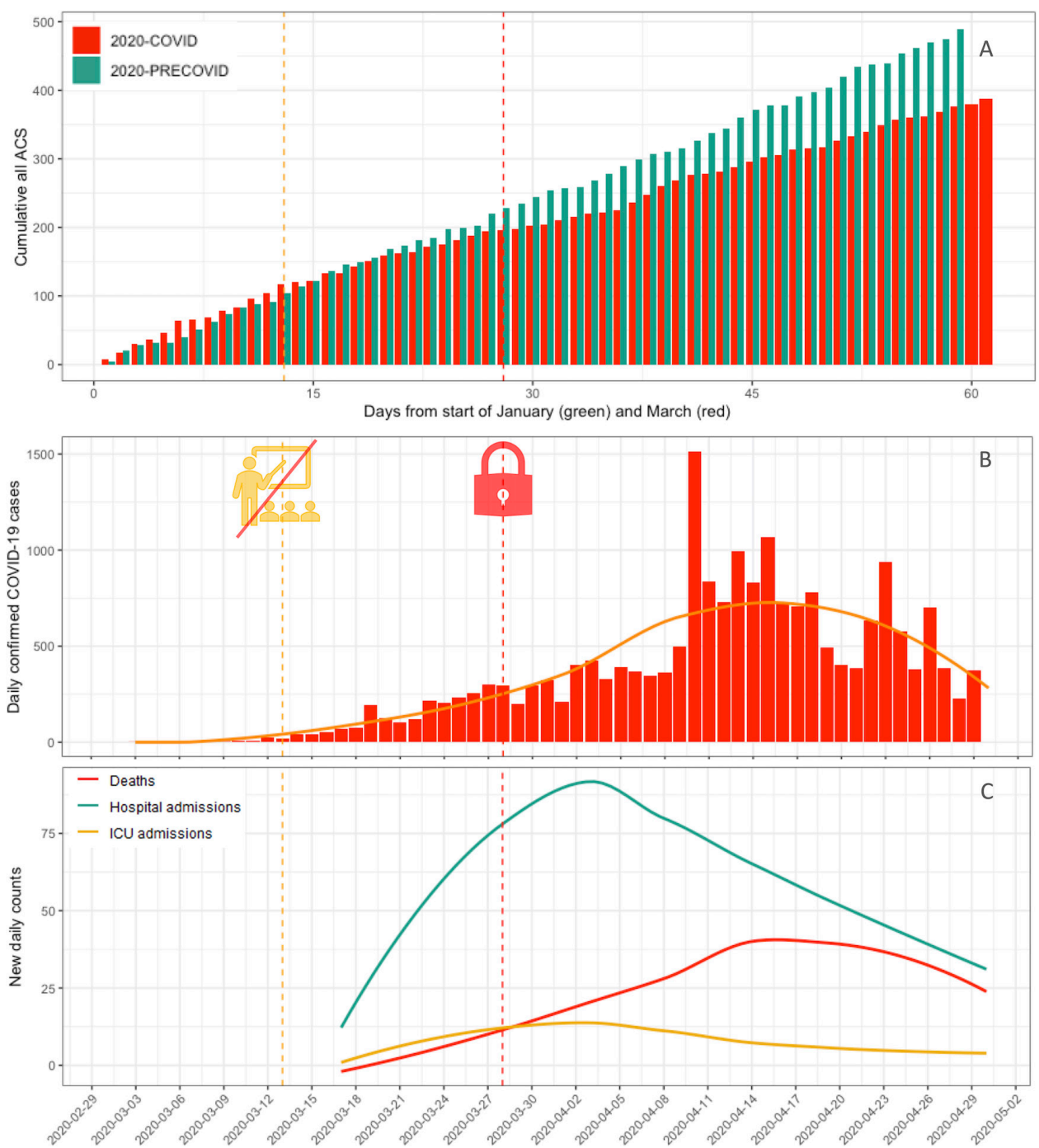

Figure 1 (A) The cumulative incidence of $\mathrm{PCl}$ procedures for the treatment of all ACS is demonstrated during 2 months preceding (green) and succeeding (red) the first confirmed COVID-19 case in Ireland over time; (B) the daily new confirmed COVID-19 cases in Ireland with the orange line representing the locally smoothed trend; (C) the locally smoothed trend of COVID-19 daily new hospital and ICU admissions and confirmed/suspected deaths over time in Ireland; the orange dotted line in $\mathrm{A}, \mathrm{B}$ and $\mathrm{C}$ represents the national closure of schools (13 March), the red dotted line represents the date of full lockdown implementation (28 March). ACS, acute coronary syndrome; ICU, intensive care unit; PCI, percutaneous coronary intervention.

PCI cases per hospital, are presented as a mean \pm SD. All analyses were performed in R V.3.6 (R Core Team, 2020).

\section{RESULTS}

After the first COVID-19 case was confirmed on 29 February 2020 in Ireland, the cumulative incidence of COVID-19-confirmed cases rose above 1000 cases by 23 March and reaching 20612 by 30 April with 1232 COVID19-related deaths at that moment (figure 1). ${ }^{10}$ For an estimated 4.90 million inhabitants, intensive care bed capacity was expanded from 255 to 411 critical care beds within the Irish public health system, with additional surge capacity of up to a total of 800 beds. ${ }^{13}$ The number of confirmed and suspected COVID-19 cases in critical care was 160 at its maximum on 4 April $2020 .^{10}$

During January and February 2020, the 2months preceding the first confirmed COVID-19 case, 490
ACS-PCI were performed for the treatment of all categories of ACS. This compares with a total of 387 ACS-PCI cases in the succeeding 2 months. The mean daily rates per centre of PCI for all ACS, STEMI and NSTE-ACS are outlined in table 1.

During the '2020 COVID-19' period, there was a $24 \%$ reduction in PCI for the treatment of all ACS as compared with the '2020 pre-COVID-19' period (IRR 0.76; 95\% CI 0.65 to $0.88 ; \mathrm{p}<0.001$ ) (table 2 ).

There was a corresponding 29\% reduction in PCI for the treatment of NSTE-ACS (IRR $0.71 ; 95 \%$ CI 0.57 to $0.88 ; \mathrm{p}=0.002$ ) and an $18 \%$ reduction in PCI for STEMI (IRR 0.82; 95\% CI 0.67 to $1.01 ; \mathrm{p}=0.061$ ), as compared with the '2020 pre-COVID-19' period (table 2). During the '2020 COVID-19' period, there was also a 22\% reduction in PCI performed for the treatment of STEMI as 
Table 1 Mean and SD of daily PCl procedures per centre for all ACS, NSTE-ACS and STEMI cases

\begin{tabular}{|c|c|c|c|}
\hline Period & Total & $\begin{array}{l}\text { Daily mean per } \\
\text { centre }\end{array}$ & \pm SD \\
\hline \multicolumn{4}{|c|}{ All ACS } \\
\hline 2020 COVID-19* & 387 & 1.25 & 1.34 \\
\hline $\begin{array}{l}2020 \text { pre- } \\
\text { COVID-19† }\end{array}$ & 490 & 1.66 & 1.66 \\
\hline \multicolumn{4}{|c|}{ NSTE-ACS } \\
\hline 2020 COVID-19* & 212 & 0.68 & 1.07 \\
\hline $\begin{array}{l}2020 \text { pre- } \\
\text { COVID-19† }\end{array}$ & 288 & 0.98 & 1.29 \\
\hline \multicolumn{4}{|c|}{ STEMI } \\
\hline 2020 COVID-19* & 175 & 0.56 & 0.77 \\
\hline $\begin{array}{l}2020 \text { pre- } \\
\text { COVID-19† }\end{array}$ & 202 & 0.68 & 0.86 \\
\hline 2019 reference $\neq$ & 436 & 0.73 & 0.92 \\
\hline 2019 Jan/Feb§ & 207 & 0.70 & 0.91 \\
\hline 2019 Mar/Aprף & 229 & 0.75 & 0.94 \\
\hline
\end{tabular}

*2020 COVID-19 is 29 February-30 April 2020 (62 days). †2020 pre-COVID-19 is 1 January-28 February 2020 (59 days). $\ddagger 2019$ reference is 1 January-30 April 2019 (120 days). \$2019 Jan/Feb is 1 January-28 February 2019 (59 days). I2019 Mar/Apr is 1 March-30 April 2019 (61 days). NSTE-ACS, non-ST elevation acute coronary syndrome; $\mathrm{PCl}$, percutaneous coronary intervention; STEMI, ST-elevation myocardial infarction.

compared with the '2019 reference' period (IRR 0.78; 95\% CI 0.65 to $0.93 ; \mathrm{p}=0.005$ ) (table 2).

To assess confounding of the results by seasonal variability between the '2020 pre-COVID-19' and '2020

Table 2 Comparison of $\mathrm{PCl}$ for the treatment of all ACS, NSTE-ACS and STEMI for the study period (2020 COVID-19) versus control period

\begin{tabular}{|c|c|c|c|}
\hline Period & $\begin{array}{l}\text { Incidence } \\
\text { rate ratio }\end{array}$ & $95 \% \mathrm{Cl}$ & $P$ value \\
\hline \multicolumn{4}{|c|}{ All ACS } \\
\hline $\begin{array}{l}2020 \text { COVID-19 to } \\
2020 \text { pre-COVID-19 }\end{array}$ & 0.76 & 0.65 to 0.88 & $<0.001$ \\
\hline \multicolumn{4}{|c|}{ NSTE-ACS } \\
\hline $\begin{array}{l}2020 \text { COVID-19 to } \\
2020 \text { pre-COVID-19 }\end{array}$ & 0.71 & 0.57 to 0.88 & 0.002 \\
\hline \multicolumn{4}{|c|}{ STEMI } \\
\hline $\begin{array}{l}2020 \text { COVID-19 to } \\
2020 \text { pre-COVID-19 }\end{array}$ & 0.82 & 0.67 to 1.01 & 0.061 \\
\hline $\begin{array}{l}2020 \text { COVID- } 19 \text { to } \\
2019 \text { reference }\end{array}$ & 0.78 & 0.65 to 0.93 & 0.005 \\
\hline $\begin{array}{l}2019 \mathrm{Jan} / \mathrm{Feb} \text { to } \\
2019 \mathrm{Apr} / \mathrm{May}\end{array}$ & 1.05 & 0.87 to 1.27 & 0.583 \\
\hline $\begin{array}{l}2020 \text { COVID-19 to } \\
2019 \text { Apr/May }\end{array}$ & 0.76 & 0.62 to 0.92 & 0.006 \\
\hline
\end{tabular}

NSTE-ACS, non-ST elevation acute coronary syndrome; PCI, percutaneous coronary intervention; STEMI, ST-elevation myocardial infarction.
COVID-19' periods (ie, to verify whether admissions change naturally over time), we compared the overall STEMI rate in January/February 2019 with that of March/April 2019. There was no significant variability between both periods (IRR 1.05 ; $95 \%$ CI 0.87 to 1.27 ; $\mathrm{p}=0.583$ ) (table 2). Results were also reproducible year on year when we considered the STEMI PCI incidence in the period of March-April 2019 as compared with the corresponding '2020 COVID-19' period, with a significant $24 \%$ lower PCI rate for STEMI in the '2020 COVID-19' period (IRR $0.76 ; 95 \%$ CI 0.62 to $0.92 ; \mathrm{p}=0.006$ ) (table 2 ).

\section{DISCUSSION}

This study demonstrates a substantial reduction in PCI procedures performed for the treatment of all ACS, NSTE-ACS and STEMI during the initial stages of the COVID-19 pandemic in Ireland. During the 2 months since the first confirmed COVID-19 case, PCI rates for the treatment of all ACS, NSTE-ACS and STEMI dropped by $24 \%, 29 \%$ and $18 \%$, respectively, with respect to the prior 2 months (figures 1 and 2). As compared with the 2019 reference period, there was a $22 \%$ reduction of PCI for STEMI during the '2020 COVID-19' period (figure 3).

These data correspond with data from other countries detailing similar reductions in STEMI cases and ACS hospital admissions. ${ }^{3-8}$ Here we highlight the impact of COVID-19 on the actual number of PCI procedures performed for the treatment of all ACS since the COVID-19 outbreak. These data are of particular relevance as it seems the pandemic affects both the number of patients presenting to hospital with ACS as well as the number of patients who undergo PCI as a treatment for ACS. It has been shown in other jurisdictions that the hospital admission rate for ACS itself has declined and the reduction in admissions is also mirrored in a downward trend in PCI rates. ${ }^{16}$ Since coronary revascularisation has a proven survival benefit in the treatment of both STEMI and NSTE-ACS, this raises concern for incremental cardiac morbidity and mortality during the initial phases of the COVID-19 pandemic.

It is difficult to fully account for this sudden and significant drop in PCI performed for the treatment of ACS among these primary PCI centres. In Ireland, where the healthcare system was not overwhelmed by COVID-19 cases, the emergency departments and primary PCI facilities remained operational without any capacity limitation. Potential factors for an observed reduction in ACS treatments include changes in lifestyle or environmental factors, such as workplace stressors or exposure to air pollution. The link between environmental pollution and cardiovascular outcomes is long established with both short-term and long-term exposures to pollutants such as $\mathrm{PM}_{2.5}$ (fine particulate matter $\leq 2.5 \mu \mathrm{m}$ in aerodynamic diameter), nitrogen dioxide and ozone linked with ACS. ${ }^{17} 18$ Indeed, there have been changes in air quality recorded during lockdowns for COVID-19, both in Ireland and abroad with nitrogen dioxide levels 


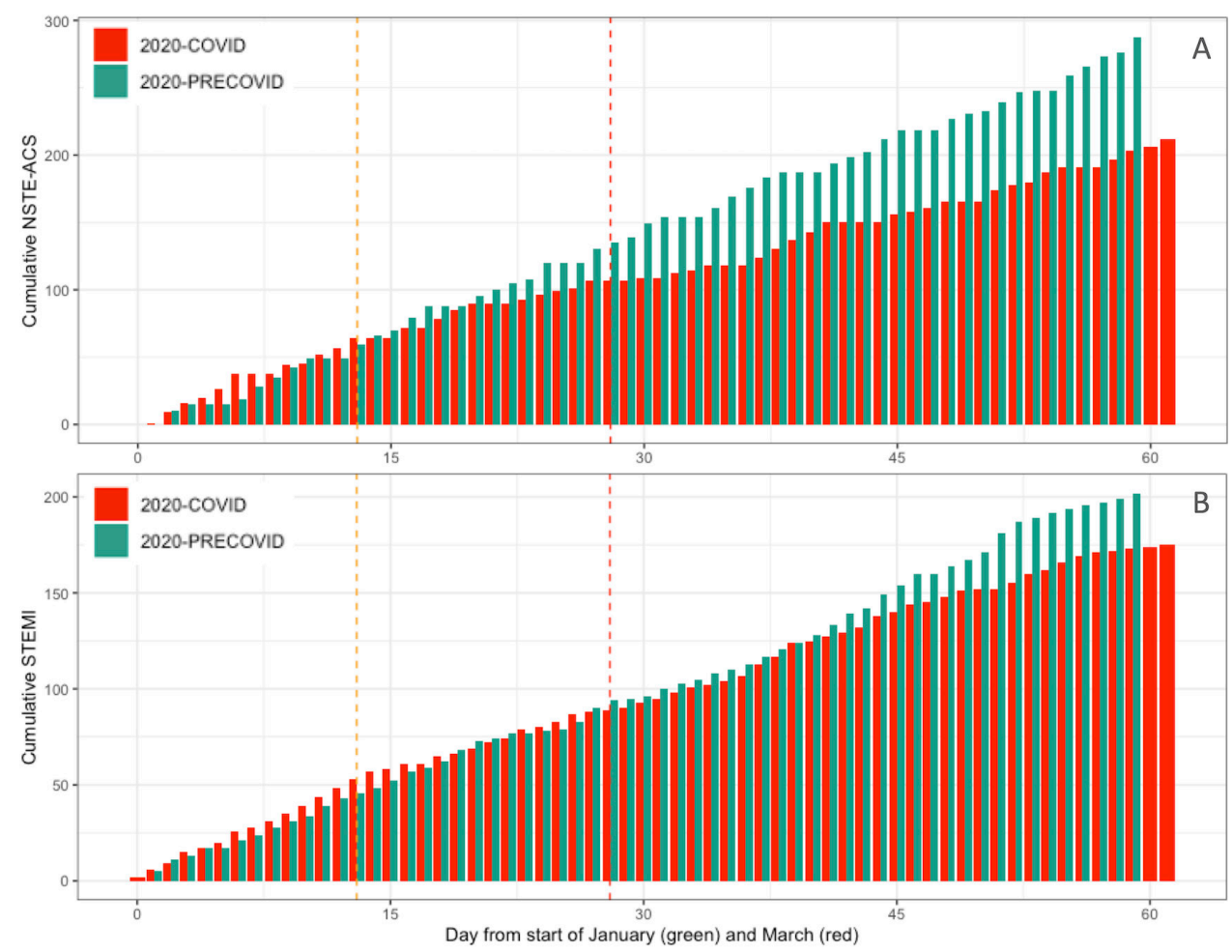

Figure 2 Cumulative incidence of PCI procedures for the treatment of NSTE-ACS and STEMI during the 2020 COVID-19 period and the 2020 pre-COVID-19 period. (A) Shows the overall cumulative incidence of PCl performed for the treatment of NSTE-ACS during 2020 pre-COVID-19 (green) and 2020 COVID-19 (red); in (B) the overall cumulative incidence of PCI performed for the treatment of STEMI during the 2020 pre-COVID-19 (green) and 2020 COVID-19 periods (red) is shown; the orange dotted line in $(A)$ and $(B)$ represents the national closure of schools, the red dotted line represents the date of full lockdown implementation. NSTE-ACS, non-ST-elevation acute coronary syndrome; PCl, percutaneous coronary intervention; STEMI, ST-elevation myocardial infarction.

in Ireland well below expected levels compared with previous years. ${ }^{19-21}$ In contrast to findings in major industrial cities worldwide, there was not a significant drop in $\mathrm{PM}_{2.5}$ in Ireland. ${ }^{22}$ However, it remains plausible that a rapid reduction in particulate and other environmental pollutants could contribute to a reduction in ACS incidence and mortality.

We must also consider the potential effect of physician selection of patients for intervention on PCI rates. A more conservative approach to patient selection could contribute to a fall in invasive intervention with more patients being managed non-invasively. Misconceptions in the required acuity of management of STEMI versus NSTE-ACS could also lead to differences in referral patterns from non-specialist centres. Assuming a tendency towards a more conservative approach to management of NSTE-ACS could explain why the drop in procedures was more exaggerated in this group. Indeed, a suggestion of a move to a lower risk profile of patient has been seen during the pandemic in other

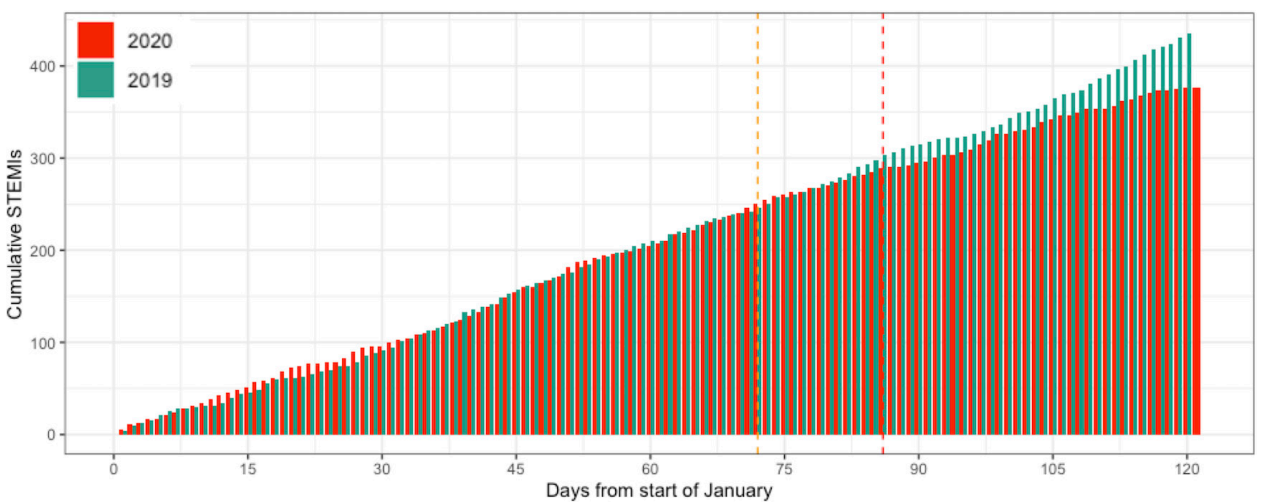

Figure 3 Cumulative incidence of PCI procedures for the treatment of STEMI comparing 2019 with 2020. The cumulative incidence of $\mathrm{PCl}$ procedures for the treatment of STEMI comparing January-April 2019 (green) with the same period in 2020 (red); the orange dotted line represents the national closure of schools, the red dotted line represents the date of full lockdown implementation. PCl, percutaneous coronary intervention; STEMI, ST-elevation myocardial infarction. 
jurisdictions that have shown drops in PCI rates for STEMI and NSTE-ACS. ${ }^{23}$

One of the major over-riding concerns however is that the true incidence of ACS in the population has remained largely unchanged during the COVID-19 pandemic and that the proportion of patients presenting to the hospital appropriately has fallen. The worry here is that a large proportion of patients with ACS may not be presenting, or delaying their presentation, to healthcare facilities despite measures to preserve the function and capacity of emergency departments and acute cardiac facilities in Ireland. The Irish Cardiac Society conducted a survey among cardiologists at the height of the pandemic and reported that the reduction in ACS presentations to hospitals was attributed to: (1) people's fear of being exposed to COVID-19 within a healthcare facility $(97 \%)$; (2) people not leaving their homes due to the government restrictions $(41 \%)$ and (3) people worried about putting a burden on the health services $(41 \%) .{ }^{24}$ Fear for the healthcare environment as well as unawareness of the risk-mitigation efforts set up by the hospitals were the overarching themes reported by patients in a series of semistructured interviews performed during the pandemic in an American population. ${ }^{25}$ Indeed, in relation to these latter assertions, cumulative incidence of PCI rates for ACS suggests further diverging of the curves the moment social distancing and lockdown measures were put in place, 2 weeks after the first confirmed COVID-19 case (figure 1).

Anecdotal evidence suggests that the reduction/delay in presenting to hospital with ACS during the COVID-19 era has resulted in an increase in the proportion of mechanical complications. ${ }^{26}$ Indeed, recent studies have documented both prolonged delays from symptom onset to first medical contact, increased door-to-balloon time and total ischaemia time for the reduced number of patients who do present to hospital. ${ }^{27} 28$

Given the reduction in acute coronary revascularisation observed in the current study and assuming the true incidence of ACS has not changed significantly, it is possible that we will yet see a future wave of new postmyocardial infarction-induced heart failure presentations and arrhythmias leading to further morbidity and mortality. It will take a significant period of time before the true measure of effect of this pandemic in a cardiovascular sense is known and we will need to monitor excess mortality figures to assess for this indirect impact caused by this pandemic.

Our study has limitations. First, we were only able to include five of six primary PCI centres in Ireland. The participating centres, however, account for more than three-quarters of all STEMI presentations in Ireland. Herein, we present the daily numbers of PCI procedures for the treatment of ACS, rather than hospital admissions for PCI. Using ACS-related PCI activity could underestimate the true incidence of ACS presenting to hospitals due to alterations in clinical practice patterns, such as an increased use of non-invasive strategies. However, our objective was to evaluate the patterns of invasive treatment of ACS during the COVID-19 pandemic. Further information on the number of ACS presentations to the participating hospitals as well as referrals for intervention from district hospitals that were treated non-invasively were not available. Additional complete clinical and mortality data were not available for all centres participating and therefore were not analysed.

In conclusion, we report a one-quarter reduction in PCI for ACS during the COVID-19 pandemic in an affected, but not overwhelmed, European healthcare system. Reasons for this reduction are numerous and varied. Clear public health messaging and measures are required to encourage patients to seek medical attention for nonCOVID-19-related illness.

\section{Author affiliations}

${ }^{1}$ Department of Cardiology, Galway University Hospitals, Galway, Ireland ${ }^{2}$ School of Medicine, National University of Ireland Galway, Galway, Ireland ${ }^{3}$ Department of Cardiology, St. James's Hospital, Dublin, Ireland ${ }^{4}$ Department of Cardiology, University of Limerick, Limerick, Ireland ${ }^{5}$ Department of Cardiology, University Hospital Limerick, Limerick, Ireland ${ }^{6}$ Department of Cardiology, University Hospital Waterford, Waterford, Ireland ${ }^{7}$ Department of Cardiology, Mater Misericordiae University Hospital, Dublin, Ireland

Twitter Niall Patrick Connolly @niallpconnolly and Khalid AlHarbi @KhalidAlHarbi85 Contributors NPC, DM and LR formed the concept, designed, wrote and revised the paper. AS did the statistical analysis, graphics, critical revision of the paper for important intellectual content and final approval of the version to be published. JC, SO, KA, TK, SA, PO, AJ, GJB, SF and DC were responsible for data acquisition, critical revision of the paper for important intellectual content and final approval of the version to be published. All authors agree to be accountable for all aspects of the work in ensuring that questions related to the accuracy or integrity of any part of the work are appropriately investigated and resolved.

Funding The authors have not declared a specific grant for this research from any funding agency in the public, commercial or not-for-profit sectors.

Competing interests DM is a consultant for Medtronic, Boston Scientific and Microport.

Patient and public involvement Patients and/or the public were not involved in the design, or conduct, or reporting, or dissemination plans of this research.

Patient consent for publication Not required.

Ethics approval Ethical approval for the study was gained from the National Research Ethics Committee (NREC) established for COVID-19-related research in Ireland.

Provenance and peer review Not commissioned; externally peer reviewed.

Data availability statement Data are available upon reasonable request. The deidentified participant data underlying this article will be shared on reasonable request to the corresponding author.

Open access This is an open access article distributed in accordance with the Creative Commons Attribution Non Commercial (CC BY-NC 4.0) license, which permits others to distribute, remix, adapt, build upon this work non-commercially, and license their derivative works on different terms, provided the original work is properly cited, appropriate credit is given, any changes made indicated, and the use is non-commercial. See: http://creativecommons.org/licenses/by-nc/4.0/.

ORCID iD

Niall Patrick Connolly http://orcid.org/0000-0002-1493-6454

\section{REFERENCES}

1 Smeeth L, Thomas SL, Hall AJ, et al. Risk of myocardial infarction and stroke after acute infection or vaccination. $N$ Engl J Med 2004;351:2611-8. 
2 Kwong JC, Schwartz KL, Campitelli MA, et al. Acute myocardial infarction after Laboratory-Confirmed influenza infection. $N$ Engl $J$ Med 2018;378:345-53.

3 Garcia S, Albaghdadi MS, Meraj PM, et al. Reduction in STsegment elevation cardiac catheterization laboratory activations in the United States during COVID-19 pandemic. J Am Coll Cardiol 2020;75:2871-2.

4 De Filippo O, D'Ascenzo F, Angelini F, et al. Reduced rate of hospital admissions for ACS during Covid-19 outbreak in northern Italy. $N$ Engl J Med 2020;383:88-9.

5 Rodríguez-Leor O, Cid-Álvarez B, Ojeda S. Impacto de la pandemia de COVID-19 sobre La actividad asistencial en cardiología intervencionista en España. Rec Interv Cardiol 2020;2:82-9.

6 Rangé G, Hakim R, Motreff P. Where have the ST-segment elevation myocardial infarctions gone during COVID-19 lockdown? Eur Heart $J$ Qual Care Clin Outcomes 2020;6:223-4.

7 De Rosa S, Spaccarotella C, Basso C, et al. Reduction of hospitalizations for myocardial infarction in Italy in the COVID-19 era. Eur Heart J 2020;41:ehaa409.

8 Metzler B, Siostrzonek P, Binder RK, et al. Decline of acute coronary syndrome admissions in Austria since the outbreak of COVID-19: the pandemic response causes cardiac collateral damage. Eur Heart $J$ 2020;41:1852-3.

9 Neumann F-J, Sousa-Uva M, Ahlsson A, et al. 2018 ESC/ EACTS guidelines on myocardial revascularization. Eur Heart $J$ 2019:40:87-165.

10 Department of Health, Ireland. Latest updates on COVID-19 (coronavirus). Available: https://www.gov.ie/en/news/7e0924-latestupdates-on-covid-19-coronavirus/ [Accessed 04 Jun 2020].

11 Health Service Executive, Ireland. National clinical programmes acute coronary syndrome. Available: https://www.hse.ie/eng/about/ who/cspd/ncps/acs/ [Accessed 24 May 2020].

12 Health Service Executive, Ireland. Report of the National clinical programme for acute coronary syndrome (ACS) on standardising treatment of patients with STEMI in 2016. Available: https://www.hse. ie/eng/about/who/cspd/ncps/acs/resources/heart-attack-care-in2016.pdf/ [Accessed 17 Feb 2021]

13 Central Statistics Office, Ireland. Population and labour force projections 2017 - 2051. Available: https://www.cso.ie/en/rele asesandpublications/ep/p-plfp/populationandlabourforceprojecti ons2017-2051/populationprojectionsresults/ [Accessed 04 Jun 2020].

14 Ibanez B, James S, Agewall S, et al. 2017 ESC guidelines for the management of acute myocardial infarction in patients presenting with ST-segment elevation: the task force for the management of acute myocardial infarction in patients presenting with ST-segment elevation of the European Society of cardiology (ESC). Eur Heart J 2018;39:119-77.
15 Roffi M, Patrono C, Collet J-P, et al. 2015 ESC guidelines for the management of acute coronary syndromes in patients presenting without persistent ST-segment elevation: Task force for the management of acute coronary syndromes in patients presenting without persistent ST-segment elevation of the European Society of cardiology (ESC). Eur Heart J 2016;37:267-315.

16 Moroni F, Gramegna M, Ajello S, et al. Collateral damage: medical care avoidance behavior among patients with myocardial infarction during the COVID-19 pandemic. JACC Case Rep 2020;2:1620-4.

17 Pope CA, Muhlestein JB, Anderson JL, et al. Short-term exposure to fine particulate matter air pollution is preferentially associated with the risk of ST-segment elevation acute coronary events. J Am Heart Assoc 2015;4:e002506.

18 Rajagopalan S, Al-Kindi SG, Brook RD. Air pollution and cardiovascular disease: JACC state-of-the-art review. J Am Coll Cardiol 2018;72:2054-70.

19 Environmental Protection Agency, Ireland. Recent trends in nitrogen dioxide (NO2) levels in air (Ireland), 2020. Available: http://www.epa. ie/newsandevents/news/pressreleases2020/name,70312,en.html [Accessed 19 Feb 2021].

20 Jephcote C, Hansell AL, Adams K, et al. Changes in air quality during COVID-19 'lockdown' in the United Kingdom. Environ Pollut 2021;272:116011.

21 He G, Pan Y, Tanaka T. The short-term impacts of COVID-19 lockdown on urban air pollution in China. Nat Sustain 2020;3:1005-11.

22 Environmental Protection Agency, Ireland. Recent trends in air pollution levels in Ireland, 2020. Available: http://www.epa.ie/ newsandevents/news/pressreleases2020/name,68631,en.html

23 Kwok CS, Gale CP, Curzen N, et al. Impact of the COVID-19 pandemic on percutaneous coronary intervention in England: insights from the British cardiovascular intervention Society $\mathrm{PCl}$ database cohort. Circ Cardiovasc Interv 2020;13:e009654.

24 Irish Cardiac Society. Acute coronary syndromes activity during COVID-19 Irish cardiac Society survey. Dublin: Irish Cardiac Society, 2020.

25 Wong LE, Hawkins JE, Langness S. Where are all the patients? addressing Covid-19 fear to encourage sick patients to seek emergency care. NEJM Catalyst Innovations in Care Delivery 2020;1:3.

26 Mafham MM, Spata E, Goldacre R, et al. COVID-19 pandemic and admission rates for and management of acute coronary syndromes in England. Lancet 2020;396:381-9.

27 Perrin N, Iglesias JF, Rey F, et al. Impact of the COVID-19 pandemic on acute coronary syndromes. Swiss Med Wkly 2020;150:w20448.

28 De Luca G, Verdoia M, Cercek M, et al. Impact of COVID-19 pandemic on mechanical reperfusion for patients with STEMI. J Am Coll Cardiol 2020;76:2321-30. 